\title{
Non-Tethered Understanding and Scientific Pluralism
}

\section{Rico Hauswald ${ }^{1}$}

Accepted: 15 December 2020 / Published online: 20 May 2021

(c) The Author(s) 2021

\begin{abstract}
I examine situations in which we say that different subjects have 'different', 'competing', or 'conflicting understandings' of a phenomenon. In order to make sense of such situations, we should turn our attention to an often neglected ambiguity in the word 'understanding'. Whereas the notion of understanding that is typically discussed in philosophy is, to use Elgin's terms, tethered to the facts, there is another notion of understanding that is not tethered in the same way. This latter notion is relevant because, typically, talk of two subjects having 'different', 'competing', or 'conflicting understandings' of a phenomenon does not entail any commitment to the proposition that these subjects understand the phenomenon in the tethered sense of the word. This paper aims, first, to analyze the non-tethered notion of understanding, second, to clarify its relationship to the tethered notion, third, to explore what exactly goes on when 'different', 'competing', or 'conflicting understandings' clash and, fourth, to discuss the significance of such situations in our epistemic practices. In particular, I argue for a version of scientific pluralism according to which such situations are important because they help scientific communities achieve their fundamental epistemic goals-most importantly, the goal of understanding the world in the tethered sense.
\end{abstract}

Keywords Understanding · Understanding's tether $\cdot$ Scientific pluralism

\section{Introduction}

There is an ambiguity in the notion of understanding that is not often examined by epistemologists and philosophers of science. Consider the following examples:

(a) Creationists have a mistaken understanding of evolution;

(b) Plato's understanding of the transmigration of souls differed significantly from Pythagoras'.

The notion of understanding that appears in (a) and (b) is obviously not the same as the notion typically discussed in contemporary epistemology and philosophy of science. It seems to be possible to have some understanding of a phenomenon such as evolution (in

Rico Hauswald

ricohauswald@gmx.de

1 Department of Philosophy, Dresden University of Technology, 01069 Dresden, Germany 
a certain sense of the word 'understanding'), even if one has no understanding at all of it (in the sense of the word that philosophers typically have in mind). Also, it makes perfect sense to utter sentence (b), even if one believes that neither Plato nor Pythagoras were even approximately correct, or that there is no such thing as the transmigration of souls. I suggest that the crucial difference between the two notions is that the one typically discussed by philosophers is a success notion, whereas the one that features in (a) and (b) is not. The former's characterization as success - recognized by almost all philosophers 1 - is due to the fact that this sort of understanding is, to use Elgin's (2007; 2012) terms, somehow sensitive or tethered to how the world is. Many scholars explain this sensitivity or tether in terms of understanding being factive in some sense. Others (nonfactivists, such as Elgin herself) reject the idea that understanding is factive, but also maintain the position that a subject understands something only if her understanding is suitably related to the world. As Elgin puts it, "[t]he issue that divides factivists and nonfactivists is not whether understanding must answer to the facts, but how it must do so" $(2017,45)$.

Now, while it is true that a certain kind of understanding has such a tether to the facts, another kind - the one that appears in the sentences (a) and (b) - neither has nor needs such a tether. For the sake of convenience, I shall call the latter concept 'non-tethered understanding' (or 'understanding $\mathrm{NT}_{\mathrm{T}}$ '), and the concept that is typically discussed by contemporary epistemologists and philosophers of science 'tethered understanding' (or 'understanding ${ }_{\mathrm{T}}$ ').

The concept of understanding $\mathrm{NT}_{\mathrm{NT}}$ is ubiquitous in the scientific literature and plays an important role in our epistemic practices, in stark contrast to the limited attention it has received from philosophers. To be sure, the existence of a non-tethered concept of understanding that differs from the one that philosophers have typically focused on has not gone completely unnoticed. For example, Hazlett $(2018,139)$ notes in passing that we "do naturally speak of someone's having a 'mistaken understanding' of something." Also, Grimm $(2011,91)$ distinguishes between what he calls 'objective understanding', which he takes to be tethered, from 'subjective understanding', which he takes to be non-tethered. Similarly, a distinction is sometimes made between (tethered) understanding and 'intelligibility'. Nevertheless, I contend that the non-tethered concept has by no means received the epistemological attention that it deserves. At best, only a few marginal notes are usually devoted to it, the common view obviously being that when we are talking about non-tethered understanding, "we are no longer talking about the kind of valuable cognitive achievement of interest to epistemologists" (Gordon 2020). While I agree that understanding ${ }_{\mathrm{NT}}$ is not an achievement or success notion like understanding ${ }_{\mathrm{T}}$ is, I do not think that this is sufficient reason to dismiss it as uninteresting or irrelevant. For the purpose of comparison, consider belief and knowledge. Belief is not an achievement or success notion like knowledge is, but it is nevertheless of eminent epistemological importance. Indeed, as we shall see later, the

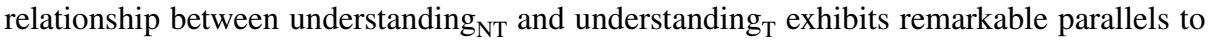
that between belief and knowledge.

\footnotetext{
${ }^{1}$ The characterization of understanding as success has been noted by Rosenberg (1981) and many other authors since then.

${ }^{2}$ According to de Regt (2017), intelligibility and unintelligibility are (extrinsic) properties of theories. To say that a theory is intelligible to a scientist is tantamount to saying that the scientist is able to work with it and use it in scientific practice (or more precisely, that the scientist "can recognize qualitatively characteristic consequences of [the theory] without performing exact calculations" (de Regt 2017, 102)). This does not imply, however, that an intelligible theory affords any understanding ${ }_{\mathrm{T}}$ of its purported subject matter (i.e., of the phenomena it deals with).
} 
One of the reasons why the notion of understanding ${ }_{\mathrm{NT}}$ is more interesting than previously recognized is that it features in sentences of the form "S1 and S2 understand P differently", "S1 has a different understanding of P than S2", or "S1 and S2 have different/ competing/conflicting understandings of P". Consider the following concrete examples:

(c) Copernicus and Ptolemy understood planetary motion differently;

(d) Different physicists had (and have) competing understandings of empty space;

(e) Priestley and Lavoisier developed conflicting understandings of combustion.

Each of these sentences can be uttered without any commitment to whether the subjects in question understand $\mathrm{T}_{\mathrm{T}}$ or understood $\mathrm{T}_{\mathrm{T}}$ planetary motion, empty space, or combustion. To be sure, at least some of these sentences may be compatible with the fact that at least some of the subjects have an understanding ${ }_{\mathrm{T}}$ of the phenomena mentioned. But the situation is complex, and in order to disentangle it, we need a better grasp of the structure of the notions of understanding ${ }_{\mathrm{T}}$ and understanding $\mathrm{NT}_{\mathrm{NT}}$, as well as the relationships between them.

The situations that we can describe by sentences of the form "S1 and S2 have different/ competing/conflicting understandings of P", or at least some of them, are akin to disagreements. Perhaps they should not be characterized as disagreements in the strict sense, ${ }^{3}$ but whether or not this is so, for our purposes it suffices to say that they are 'disagreementlike', or that they are instances of what Audi (2013) calls 'cognitive disparity'- "a kind of difference-usually also yielding a tension—between cognitive elements" (Audi 2013, 204).

This paper is motivated by two core ideas: The first idea is that the relationship between

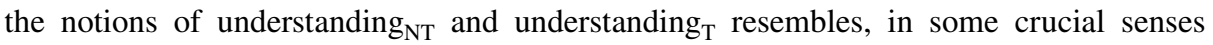
the relationship between belief and knowledge. The second idea is that there is a parallel between the way in which doxastic disagreements, i.e., the presence of opposing beliefs, in an epistemic (e.g., scientific) community can foster the acquirement of knowledge in this community, and the way in which the presence of opposing understanding $\mathrm{s}_{\mathrm{NT}}$ can foster the acquirement of understanding $\mathrm{T}_{\mathrm{T}}$. The latter idea amounts to a special version of epistemic or scientific pluralism, which I develop in detail in Sect. 5. Before advocating this pluralist position, however, I first need to clarify the conceptual resources necessary to its formulation-in particular, the distinction between understanding $\mathrm{T}_{\mathrm{T}}$ and understanding $\mathrm{NT}_{\mathrm{NT}}$ and the idea of different understanding $\mathrm{s}_{\mathrm{NT}}$ being in tension or opposition to one another, which, unlike the notions of belief, knowledge, or doxastic disagreement, are not part of the standard philosophical discourse. This is what I do in Sects. 2 to 4. In Sect. 2, I start by briefly reviewing the various definitions of understanding $\mathrm{T}_{\mathrm{T}}$ that have been offered in the recent philosophical literature. I do not do this for the purpose of evaluating these definitions or identifying what I take to be the most promising ones. In contrast, I remain deliberately neutral as to which of them is better and which is worse, and this neutrality is indeed an important part of this paper's strategy—namely, to characterize understanding ${ }_{\mathrm{NT}}$

\footnotetext{
3 It might be argued that a disagreement in the strict sense is a situation in which two subjects have opposing beliefs. However, as some authors have observed, there also seem to exist situations that we naturally tend to describe as disagreements and which involve attitudes other than belief. For example, Huvenes (2013) argues that a sentence like "S1 likes haggis, whereas S2 dislikes it" may well be said to qualify as a case of disagreement. This sentence describes a case involving 'contrasting attitudes', but the contrast is not between instances of belief, but of liking. For further examples of disagreement that deviate from the paradigmatic doxastic case, as well as a critical discussion of those positions that hold that genuine disagreement is confined to the paradigmatic case, see Huvenes (2017).
} 
by demarcating it from understanding ${ }_{\mathrm{T}}$ (not from understanding ${ }_{\mathrm{T}}$ as defined by a particular existing theory), and then to explore the relationship between these two concepts. Therefore, the reason why I shall discuss the various existing definitions of understanding ${ }_{\mathrm{T}}$ is to identify something similar to their least common denominator and to formulate a rather general definitional scheme of understanding ${ }_{\mathrm{T}}$, which can then (in Sect. 3) be used to introduce understanding $_{\mathrm{NT}}$, demarcate the latter from the former, and explore the relationship between them. In Sect. 4, I then suggest an account of what exactly happens in situations in which one subject is said to have a certain understanding ${ }_{\mathrm{NT}}$ of some phenomenon, whereas another subject is said to have a different, competing, or conflicting understanding $\mathrm{NT}_{\mathrm{NT}}$ of it, before I finally examine the epistemological significance of such situations and their relevance for science in Sect. 5.

\section{The Notion of Understanding in Contemporary Epistemology and Philosophy of Science}

Recent epistemology and philosophy of science have seen a remarkable shift of interest from traditional topics such as the concept of knowledge to that of understanding. The philosophers in this debate ${ }^{4}$ usually distinguish between different kinds of understanding, most importantly objectual understanding, i.e. understanding of a certain subject matter or phenomenon $\mathrm{P}$ (such as evolution or climate change), and understanding-why, i.e. understanding why a certain event occurred or why a certain state of affairs obtains (for example, why the stock market crashed in 2008, or why the Moon orbits the Earth). For convenience sake, in this paper I shall concentrate on objectual understanding, but it should be relatively easy to apply mutatis mutandis my considerations to explanatory understanding as well. ${ }^{5}$

My contention in this paper is that there is, in addition to the concept of objectual understanding that has been studied by epistemologists and philosophers of scienceunderstanding $_{\mathrm{T}}$ as I have referred to it-, another, equally relevant concept of (objectual) understanding that, unlike the first one, neither has nor needs a tether to the facts. One of my aims is to analyze this concept-understanding $\mathrm{NT}_{\mathrm{NT}}$ and explore its relationship to that of understanding $\mathrm{T}_{\mathrm{T}}$. But first we need some clarity about the notion of understanding $\mathrm{T}_{\mathrm{T}}$. The problem is, of course, that much of the debate concerns exactly the question of how this concept should be defined, and a considerable number of alternative definitions have already been proposed. Given this situation, and since my primary focus is on understanding $_{\mathrm{NT}}$, the best strategy, in my view, is to use an account of understanding $\mathrm{T}_{\mathrm{T}}$ that is as neutral as possible with regard to the various definitions that have been proposed in the literature, while still being informative enough to allow its demarcation from understanding $_{\mathrm{NT}}$. In other words, I shall here neither develop a new concrete definition of understanding ${ }_{\mathrm{T}}$ nor commit myself to any one of the existing proposals. Rather, my

\footnotetext{
${ }^{4}$ For some noteworthy contributions to the current debate on understanding, see the articles in de Regt et al. (2009), Grimm et al. (2017), and Grimm (2018). For an overview, see Gordon (2020).

${ }^{5}$ For example, note that we observe a distinction between a tethered and non-tethered notion in relation to explanatory understanding as well. Two subjects can be said to have an understanding ${ }_{\mathrm{T}}$ of why the stock market crashed in 2008 or why the Moon orbits the Earth, and they can be said to have different, competing, or conflicting understandings $\mathrm{NT}_{\mathrm{NT}}$ of why the stock market crashed in 2008 or why the Moon orbits the Earth; and when one attributes such understandings ${ }_{\mathrm{NT}}$ to them, one does not commit oneself to whether or not they understand $\mathrm{T}_{\mathrm{T}}$ why the stock market crashed or why the Moon orbits the Earth.
} 
strategy is to use a sort of general definitional scheme or template that is intended to be compatible with a broad variety of concrete definitions as proposed in the philosophical literature (though I shall not commit myself to the view that all existing proposals are compatible to it).

The definitional scheme that I am going to suggest presupposes that a subject who has understanding ${ }_{\mathrm{T}}$ of a phenomenon needs some mental representation of that phenomenon, which can be a theory, model or similar entity (I take this assumption to be relatively uncontroversial; a similar assumption is made, for example, in the overview article by Baumberger et al. 2017). Furthermore, I take it that any comprehensive account of understanding ${ }_{\mathrm{T}}$ should make some assertions about, first, the subject's attitude towards the representation; second, the subject's epistemic warrant for having her attitude towards the representation; third, the cognitive tasks that the subject needs to be able to exercise in relation to the representation; and fourth, the relationship between the representation and the world. Accordingly, my definitional scheme has four components, each of which corresponds to a fundamental dimension or aspect of the concept of understanding ${ }_{\mathrm{T}}$ : an epistemic-pro-attitude component, a warrant component, a cognitive component, and a tether component:

\section{$\left(\mathrm{UND}_{\mathrm{T}}\right)$ Subject $\mathrm{S}$ has an understanding $\mathrm{T}_{\mathrm{T}}$ of phenomenon $\mathrm{P}$ iff}

(1) S has a suitable epistemic pro-attitude towards a representation R of $\mathrm{P}$ (epistemic-proattitude component),

(2) S's epistemic pro-attitude has the right sort of warrant (warrant component),

(3) $\mathrm{S}$ is able to perform a characteristic set of cognitive tasks with regard to $\mathrm{R}$ (cognitive component),

(4) $\mathrm{R}$ stands in a suitable relation to $\mathrm{P}$ (i.e., $\mathrm{R}$ is correct) (tether component).

As already indicated, $\mathrm{UND}_{\mathrm{T}}$ is deliberately unspecific as to what exactly a suitable epistemic pro-attitude, the right sort of warrant, a set of characteristic cognitive abilities, and a suitable relation between $\mathrm{R}$ and $\mathrm{P}$ are. The scheme is meant to be a sort of smallest common denominator about which a wide variety of contributors to the debate on understanding $\mathrm{T}_{\mathrm{T}}$ can agree. ${ }^{6}$ But in order to better grasp how the scheme is supposed to work, it is useful to briefly consider how the four components could possibly be specified. As for the epistemic-pro-attitude component, one possibility is to require that a subject who understands $\mathrm{T}_{\mathrm{T}} \mathrm{P}$ needs to believe that $\mathrm{R}$ is correct (this would be in line with, e.g., Kvanvig 2003 or Pritchard 2009). Instead of full belief, it is also possible to require an acceptance of R's correctness (for defenses of acceptance-based views of understanding ${ }_{\mathrm{T}}$, see Dellsén 2016a; Baumberger and Brun 2017; Elgin 2017). A very weak position is defended by Wilkenfeld (2017), who only requires a positive degree of belief. The term 'epistemic proattitude' is supposed to cover all these suggestions.

\footnotetext{
${ }^{6}$ Sure enough, many contributions to the debate have focused only on particular aspects of the concept of understanding $_{\mathrm{T}}$ (i.e. on the specification of either the epistemic-pro-attitude component, the warrant component, the cognitive component, or the tether component), while remaining silent about the other aspects. However, I take it that upon reflection many authors would agree that any comprehensive account of the notion of understanding ${ }_{\mathrm{T}}$ should include a treatment of all four aspects, and that $\mathrm{UND}_{\mathrm{T}}$ provides an integrative framework for such a comprehensive account.
} 
Most accounts of understanding ${ }_{\mathrm{T}}$ further demand the subject's epistemic pro-attitude to be justified or warranted in some sense. For example, for those theories that claim that understanding $_{\mathrm{T}}$ is a species of knowledge (such as Grimm 2006; Khalifa and Gadomski 2013; or Kelp 2017), it would be natural to require that the subject's belief in the correctness of $\mathrm{R}$ is justified and not 'gettierized'. ${ }^{7}$ Other accounts reject the notion that understanding $_{\mathrm{T}}$ is a species of knowledge, but still maintain that the subject's belief in or acceptance of R's correctness requires some sort of justification and/or the absence of certain forms of epistemic luck (see, for example, Kvanvig 2003; Pritchard 2009; Baumberger and Brun 2017). Wilkenfeld (2017) also requires the subject's positive degree of belief to be justified. ${ }^{8}$

Depending on which concrete approach is assumed to be adequate, the cognitive component can be specified by using such concepts as 'manipulating', 'grasping', or 'inferring'. If $S$ understands $\mathrm{T}_{\mathrm{T}} \mathrm{P}$, then $\mathrm{S}$ can manipulate $\mathrm{R}$ in the right sorts of ways (Grimm 2010; Wilkenfeld 2013), and/or grasp certain dependence relations (Kvanvig 2003; Strevens 2013; Gijsbers 2013), and/or draw certain inferences (Hills 2009; Newman 2012), and/or give relevant explanations in S's own words and follow the explanations given by someone else (Hills 2009).

Finally, as for the fourth component, the spectrum of positions defended in the literature ranges from a 'strong', to a 'moderate', to a 'non-factivity'. 'Strong factivity' means that $\mathrm{R}$ needs to be completely true. By contrast, proponents of 'moderate factivity' (such as Kvanvig 2003; Mizrahi 2012) argue that only certain essential elements of $\mathrm{R}$ need to be true, while the falsity of other elements are compatible with the subject's understanding ${ }_{\mathrm{T}}$. Accordingly, a theory whose central assumptions are true may qualify as a suitable representation, even though some of its more peripheral assumptions are false. Finally, according to the 'non-factivity' view, $\mathrm{R}$ does not need to be true at all. Proponents of this position (e.g., Elgin 2007; 2012; 2017) regularly invoke, for example, scientific models, which can be highly idealized and still facilitate understanding ${ }_{\mathrm{T}}$. Nevertheless, even proponents of this weak position maintain that $\mathrm{R}$ needs to stand in some suitable relationship to reality. As Elgin puts it: "understanding somehow answers to the facts" (Elgin 2007, 33). I shall also speak of a 'correct representation', which means that the representation satisfies the conditions of the fourth component, regardless of whether it is specified in terms of strong, moderate, or non-factivity. ${ }^{9}$

\footnotetext{
${ }^{7}$ It is worth noting that once one takes understanding ${ }_{\mathrm{T}}$ to be a species of knowledge, it also follows that the tether component has been met trivially, since knowing that $\mathrm{R}$ is correct implies (or presupposes) that $\mathrm{R}$ is correct.

${ }^{8}$ While most accounts of understanding ${ }_{\mathrm{T}}$ require the subject's epistemic pro-attitude to be justified, Dellsén (2016a) has argued that understanding ${ }_{\mathrm{T}}$ does not require any form of justification. If this is correct, it would not be necessary to include a warrant component in $\mathrm{UND}_{\mathrm{T}}$. However, since none of my subsequent arguments about understanding $\mathrm{NT}_{\mathrm{NT}}$ and its relationship to understanding $\mathrm{T}_{\mathrm{T}}$ depend crucially on whether understanding $_{\mathrm{T}}$ is compatible with the absence of any form of epistemic warrant, I shall henceforth ignore this possibility.

${ }^{9}$ One might worry whether $\mathrm{UND}_{\mathrm{T}}$ really is differentiated enough to account for the complex nature of understanding $\mathrm{T}_{\mathrm{T}}$. In particular, some authors have admitted that a subject can understand ${ }_{\mathrm{T}}$ a phenomenon $\mathrm{P}$ by using a highly idealized representation of $\mathrm{P}$, but have argued that this requires the subject to believe certain aspects or parts of R (namely those parts that truly represent R) and to merely accept certain other aspects or parts of R (especially those parts that do not truly represent P) (e.g., see Greco 2014; Lawler 2019; or Rice 2019 for such a view). However, it is easy to fit this view into $\mathrm{UND}_{\mathrm{T}}$ in the following way: if $R$ is an idealized representation of $P$, one can decompose it into two parts, $R_{1}$ and $R_{2}$, where the former includes those parts of $R$ that truly represent $P$, while the latter includes those parts of $R$ that do not truly represent $\mathrm{P}$; subject $\mathrm{S}$ then has an understanding ${ }_{\mathrm{T}}$ of phenomenon $\mathrm{P}$ iff (i) $\mathrm{S}$ has a suitable epistemic pro-attitude towards $R_{1}$ (e.g., $S$ believes $R_{1}$ ) and $S$ has a suitable epistemic pro-attitude towards $R_{2}$ (e.g., $S$
} 
In the next section I examine non-tethered understanding and argue that its relationship to tethered understanding resembles, in several crucial ways, the relationship between belief and knowledge. In particular, I argue that understanding ${ }_{\mathrm{T}}$ is tethered, while understanding $_{\mathrm{NT}}$ is not, much like knowledge is factive, while belief is not. And just as belief is an ingredient of knowledge, understanding $\mathrm{NT}_{\mathrm{NT}}$ is an ingredient of understanding $\mathrm{T}_{\mathrm{T}}{ }^{10}$

\section{Non-Tethered Understanding}

As we have seen in the introduction, there is a kind of understanding that can be attributed to a subject without any commitment to whether the subject understands ${ }_{\mathrm{T}}$ the phenomenon in question. How should this concept be defined? As already indicated, one crucial feature is that it does not need any sensitivity to the facts, and therefore a definitional scheme of understanding $_{\mathrm{NT}}$ will lack a tether component. Furthermore, I suggest that a definitional scheme of understanding ${ }_{\mathrm{NT}}$ does not require a warrant component either. While a subject who understands ${ }_{\mathrm{T}}$ needs to justifiably believe or justifiably accept that $\mathrm{R}$ is correct, it seems to be possible to attribute an understanding ${ }_{\mathrm{NT}}$ of a phenomenon to a subject even if the subject's belief in or acceptance of R's correctness is not justified (however, the fact that the subject's belief or acceptance is justified is of course compatible with attributing an understanding $\mathrm{NT}_{\mathrm{NT}}$ to her). Therefore, while interpreting understanding $\mathrm{T}_{\mathrm{T}}$ as a species of knowledge can perhaps be a viable theoretical option, it is not a viable option to interpret understanding $_{\mathrm{NT}}$ as a species of knowledge, since, in the case of understanding $\mathrm{NT}_{\mathrm{NT}}$, neither the subject's epistemic pro-attitude needs to be justified, nor does the representation she uses have to be correct.

As far as the other components are concerned, it seems that the two concepts are quite similar. If we say that a subject $\mathrm{S}$ has an understanding $\mathrm{NT}_{\mathrm{N}}$ of a phenomenon $\mathrm{P}$, we seem to say, first, that $\mathrm{S}$ has an epistemic pro-attitude toward a representation $\mathrm{R}$ of $\mathrm{P}$, and therefore a definitional scheme of understanding ${ }_{\mathrm{NT}}$ needs an epistemic-pro-attitude component, and second that $\mathrm{S}$ is able to perform a number of characteristic cognitive tasks with regard to $\mathrm{R}$, and therefore it also needs a cognitive component. These considerations suggest the following definitional schema for understanding $\mathrm{NT}_{\mathrm{T}}$ :

\section{$\left(\mathrm{UND}_{\mathrm{NT}}\right)$ Subject $\mathrm{S}$ has an understanding $\mathrm{NT}_{\mathrm{NT}}$ of phenomenon $\mathrm{P}$ iff}

(1) S has a suitable epistemic pro-attitude towards a representation $\mathrm{R}$ of $\mathrm{P}$ (epistemic-proattitude component),

(2) $\mathrm{S}$ is able to perform a characteristic set of cognitive tasks with regard to $\mathrm{R}$ (cognitive component).

Footnote 9 (continued)

accepts $\mathrm{R}_{2}$ ); (ii) S's epistemic pro-attitudes have the right sort of warrant; (iii) $\mathrm{S}$ is able to perform a characteristic set of cognitive tasks with regard to $\mathrm{R}_{1}$ and $\mathrm{R}_{2}$; (iv) $\mathrm{R}_{1}$ stands in a suitable relation to $\mathrm{P}$ (e.g., $\mathrm{R}$ is correct in terms of strong factivity) and $\mathrm{R}_{2}$ stands in a suitable relation to $\mathrm{P}$ (e.g., $\mathrm{R}$ is correct in terms of non-factivity).

${ }^{10}$ Note that the terms 'tethered' and 'correct', as I shall use them, are not synonymous. If we compare the relationship between understanding $\mathrm{T}_{\mathrm{T}}$ and understanding $\mathrm{NT}_{\mathrm{T}}$ to that between knowledge and belief, we could say that the tethered/non-tethered distinction plays a similar role with respect to the former, as does the factive/non-factive distinction with respect to the latter. Just as belief is non-factive, understanding NT $_{1}$ is non-tethered. However, this does not exclude the possibility that a belief is true or that an instance of understanding $\mathrm{NT}_{\mathrm{NT}}$ involves a correct representation. 
That $\mathrm{UND}_{\mathrm{NT}}$ needs a cognitive component might not be obvious (could a subject's understanding $_{\mathrm{NT}}$ not be a mere representation of a phenomenon?, one might ask), but it can be made plausible by recognizing the parallel between how understanding ${ }_{\mathrm{T}}$ can be (or rather, cannot be) transmitted through testimony, and how understanding $\mathrm{NT}_{\mathrm{NT}}$ can be (or cannot be). Suppose that $\mathrm{S}$ knows nothing about phenomenon $\mathrm{P}$ and understands ${ }_{\mathrm{T}}$ nothing about it. Then, an expert on $\mathrm{P}$ tells $\mathrm{S}$ an isolated proposition $\mathrm{p}$ about $\mathrm{P}$ (or a set of isolated propositions that includes $\mathrm{p}$ as a member). Given that propositional knowledge can be transferred through testimony, it seems that $\mathrm{S}$ now is in a position to know $\mathrm{p}$ and the other propositions (if they are true). If these propositions qualify as a correct representation of $\mathrm{P}$, and if $\mathrm{S}$ has a warranted epistemic pro-attitude towards them, she fulfills three of the four conditions of $\mathrm{UND}_{\mathrm{T}}$. However, unless $\mathrm{S}$ grasps any connections between them (or is able to fulfill whatever cognitive tasks are necessary for understanding ${ }_{\mathrm{T}}$ ), it would not be correct to attribute any understanding $\mathrm{T}_{\mathrm{T}}$ of $\mathrm{P}$ to $\mathrm{S}$. Given that the ability to perform these cognitive tasks cannot easily be transferred from one subject to another, it follows that, as Gordon puts it, "understanding [i.e., understanding ${ }_{\mathrm{T}}$ ] can't simply be given to another in the way knowledge can" (Gordon 2017, 298; emphasis in original). I think that a similar case can be made for non-tethered understanding as well. Suppose again that $S$ is initially completely uninformed about $\mathrm{P}$ and has neither an understanding $\mathrm{T}_{\mathrm{T}}$ nor an understanding $\mathrm{NT}_{\mathrm{NT}}$ of $\mathrm{P}$, and is now told by another subject that $\mathrm{p}$ and the other propositions about $\mathrm{P}$ are true. To better capture our intuitions about the cognitive component, we may now assume that these propositions are incorrect. However, let us suppose that $\mathrm{S}$ nevertheless has a suitable epistemic pro-attitude towards them. Now, if $S$ is able to fulfill a suitable set of cognitive tasks with regard to these propositions, $\mathrm{S}$ could, in a conversion about $\mathrm{P}$, naturally say something like "As I understand it, p". It would also be possible to say things like "On S's understanding, p", or "According to S's understanding, p". However, if S is not able to fulfill the necessary cognitive tasks (if the propositions are nothing but isolated bits of information for her), it would be very strange to utter such sentences. Thus, intuitively, we would not attribute any understanding $\mathrm{N}_{\mathrm{NT}}$ of $\mathrm{P}$ to $\mathrm{S}$, unless $\mathrm{S}$ is able to fulfill a suitable set of cognitive tasks with regard to the propositions.

Another concern one might have about the cognitive component is the following: Strevens (2013) has proposed that the 'grasping' that many philosophers in the debate around understanding ${ }_{\mathrm{T}}$ consider to be of central importance is already factive. If this be the case, using the notion of grasping might well be a natural way of specifying the cognitive component of $\mathrm{UND}_{\mathrm{T}}$, but it could not possibly be used to specify the cognitive component of $\mathrm{UND}_{\mathrm{NT}}$ because in that case grasping would imply (or presuppose) that $\mathrm{R}$ is correct, and the absence of a correctness requirement (i.e., the absence of the tether component) is exactly what is distinctive about understanding ${ }_{\mathrm{NT}}$. However, as Strevens also argues, it is easy to decompose the notion of grasping - provided that it really is factive-into a purely (non-factive) cognitive part (which Strevens refers to as 'grasping*') and a condition that ensures the correctness of what is grasped. For now, I shall not take a position on whether the 'ordinary' notion of grasping is really factive or not. Instead, I wish to argue that if 'grasping' should be factive, and provided that one wants to use it to analyze the concepts of understanding $\mathrm{T}_{\mathrm{T}}$ and understanding $\mathrm{NT}_{\mathrm{N}}$, a natural way to do this is to use the notion of grasping* within the cognitive components of $\mathrm{UND}_{\mathrm{T}}$ and $\mathrm{UND}_{\mathrm{NT}}$, while the tether component of $\mathrm{UND}_{\mathrm{T}}$ does the work of ensuring that what is grasped really is correct. In other words, the cognitive components of $\mathrm{UND}_{\mathrm{T}}$ and $\mathrm{UND}_{\mathrm{NT}}$ would be identical insofar as they are specified using the notion of grasping*: when a subject $\mathrm{S}$ has an understanding $\mathrm{NT}_{\mathrm{N}}$ of a phenomenon $\mathrm{P}, \mathrm{S}$ grasps* something about a representation of $\mathrm{P}$; and when $\mathrm{S}$ has understanding $_{\mathrm{T}}$ of $\mathrm{P}, \mathrm{S}$ similarly grasps* something about a representation of $\mathrm{P}$, but, in 
addition, we require this representation to be correct (whereby this requirement is stated in the tether component, not in the cognitive component).

One might still worry about how the cognitive component is actually supposed to work in $\mathrm{UND}_{\mathrm{NT}}$, given that $\mathrm{UND}_{\mathrm{NT}}$ does not require $\mathrm{R}$ to be a correct representation of $\mathrm{P}$. In my view, a plausible answer to this question is the following. The characteristic set of cognitive tasks mentioned in $\mathrm{UND}_{\mathrm{NT}}$ is the set $\mathrm{X}$ of cognitive tasks for which the following holds: if $\mathrm{R}$ were a correct representation of $\mathrm{P}, \mathrm{S}$ would need to be able to perform the tasks included in $\mathrm{X}$ in order to achieve understanding ${ }_{\mathrm{T}}$ of $\mathrm{P}$. For example, in order to attribute $\mathrm{S}$ an understanding ${ }_{\mathrm{NT}}$ of combustion based on phlogiston theory, $\mathrm{S}$ needs to be able to perform those cognitive tasks that, if phlogiston theory were correct, $\mathrm{S}$ would need to be able to perform in order to achieve understanding ${ }_{\mathrm{T}}$ of combustion.

With these considerations in mind, how should the relationship between understanding $_{\mathrm{NT}}$ and understanding $\mathrm{T}_{\mathrm{T}}$ be described? I think it is instructive to compare this relationship with that between belief and propositional knowledge. Looking at $\mathrm{UND}_{\mathrm{T}}$ and $\mathrm{UND}_{\mathrm{NT}}$, one might say that understanding $\mathrm{NT}_{\mathrm{T}}$ is an ingredient of understanding $\mathrm{T}_{\mathrm{T}}$ in a similar way in which belief is an ingredient of knowledge. Knowledge is belief plus something else, and understanding $\mathrm{T}_{\mathrm{T}}$ is understanding $\mathrm{NT}_{\mathrm{N}}$ plus something else. In particular, a belief must be true in order to amount to knowledge; similarly, the representation's correctness is something that is required for understanding $\mathrm{T}_{\mathrm{T}}$, but not for understanding $\mathrm{NT}_{\mathrm{NT}}$. Exactly what else is needed to turn a true belief into knowledge is a source of dispute among epistemologists (well-known proposals are, of course, that the belief must be justified and nongettierized, or the result of a reliable belief-forming process). As for understanding $\mathrm{T}_{\mathrm{T}} /$ understanding $_{\mathrm{NT}}$, an additional requisite of understanding $\mathrm{T}_{\mathrm{T}}$ is whatever is stated in the warrant component of $\mathrm{UND}_{\mathrm{T}}{ }^{11}$

Note that it is possible to say that a subject $\mathrm{S}$ has an understanding $\mathrm{NT}_{\mathrm{N}}$ of $\mathrm{P}$ without understanding $_{\mathrm{T}}$ it at all. This would be the case if $\mathrm{S}$ uses an incorrect representation (i.e., a representation that does not stand in a suitable relationship to $\mathrm{P}$ ) or if S's epistemic proattitude is not warranted. For example, $\mathrm{S}$ arguably can achieve no understanding $\mathrm{T}_{\mathrm{T}}$ of combustion on the basis of phlogiston theory (assuming that phlogiston theory is not a correct representation of combustion), but $\mathrm{S}$ can develop some understanding $\mathrm{NT}_{\mathrm{NT}}$ of it on the basis of phlogiston theory. It is probably in such situations that we say the subject has a 'mistaken understanding' of the phenomenon. ${ }^{12}$

\footnotetext{
11 If understanding ${ }_{\mathrm{T}}$ should not require any form of justification at all (see footnote 8 ), it seems that understanding $\mathrm{T}_{\mathrm{T}}$ is nothing more than an understanding $\mathrm{NT}_{\mathrm{T}}$ that includes a correct representation.

12 Note, however, that even an incorrect representation can be the object of someone's understanding ${ }_{\mathrm{T}}$.

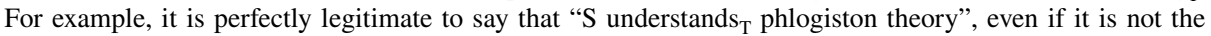
case that $\mathrm{S}$ understands ${ }_{\mathrm{T}}$ combustion. As Elgin $(2017,46)$ puts it: "it is possible for an account [i.e., a representation] to be the object of understanding [i.e., understanding ${ }_{\mathrm{T}}$ ] even if, owing to its untenability, it affords no understanding [i.e., understanding ${ }_{\mathrm{T}}$ ] of its purported subject matter." Similarly, de Regt emphasizes that both correct and incorrect theories can be intelligible to scientists (where a theory is 'intelligible' to a scientist if she understands ${ }_{\mathrm{T}}$ it; see de Regt 2017, 40). While I fully agree with Elgin, de Regt, and other authors that having an understanding ${ }_{\mathrm{T}}$ of a phenomenon $\mathrm{P}$ should not be confused with having an understanding $_{\mathrm{T}}$ of a (perhaps incorrect) representation of $\mathrm{P}$, I maintain that in order to obtain a complete picture, we should also take into account non-tethered understanding and distinguish four different aspects: (1) having an understanding $\mathrm{T}_{\mathrm{T}}$ of phenomenon $\mathrm{P}$, (2) having an understanding $\mathrm{T}_{\mathrm{T}}$ of a representation $\mathrm{R}$ of $\mathrm{P}$, (3) having an understanding $\mathrm{NT}_{\mathrm{NT}}$ of $\mathrm{P}$, and (4) having an understanding $\mathrm{NT}_{\mathrm{NT}}$ of a representation R of P. (1), but
} 
It is also worth noting that it is possible to say that two subjects S1 and S2 have different understanding $\mathrm{s}_{\mathrm{NT}}$ of $\mathrm{P}$, without implying anything about whether anyone, both, or none of them understand $\mathrm{T}_{\mathrm{T}} \mathrm{P}$. Conversely, however, it is not possible that a subject understands $\mathrm{s}_{\mathrm{T}} \mathrm{P}$ without having some understanding $\mathrm{NT}_{\mathrm{NT}}$ of $\mathrm{P}$.

\section{Different, Competing, and Conflicting Understandings $s_{\mathrm{NT}}$}

Now, what happens in cases in which two subjects are said to have different, competing, or conflicting understandings $\mathrm{S}_{\mathrm{NT}}$ of a phenomenon P? On reflection, I think it is plausible to explicate such situations by saying that the essential feature of them is that the subjects use different, competing, or conflicting representations of $\mathrm{P}$. This suggests the following definitional scheme:

(DIFF) S1 and S2 have different/competing/conflicting understandings $\mathrm{NT}_{\mathrm{NT}}$ of $\mathrm{P}$ iff

(1) (a) S1 has a suitable epistemic pro-attitude towards a representation R1 of P,

(b) S1 is able to perform a characteristic set of cognitive tasks with regard to R1,

(2) (a) S2 has a suitable epistemic pro-attitude towards a representation R2 of P,

(b) S2 is able to perform a characteristic set of cognitive tasks with regard to R2,

$\mathrm{R} 1$ and $\mathrm{R} 2$ are different/competing/conflicting.

One might object that differences between S1 and S2's representations are not the only possible differences between their understandings ${ }_{\mathrm{NT}}$. For example, if S1 and S2 share the same representation $\mathrm{R}$, they could still differ with regards to their epistemic pro-attitude towards R or the warrant they have for their attitudes. Of course, both need to have a proattitude that is sufficiently strong. For example, if one takes a positive degree of belief to be the epistemic pro-attitude required for understanding ${ }_{\mathrm{NT}}$, both $\mathrm{S} 1$ and $\mathrm{S} 2$ need a positive degree of belief towards the proposition that $\mathrm{R}$ is correct. Nevertheless, it is possible that one of them has a stronger epistemic pro-attitude than the other. For example, while S1 might simply have an (unjustified) positive degree of belief towards the proposition that $\mathrm{R}$ is correct, S2 might (justifiably) accept or believe that $\mathrm{R}$ is correct.

Another possibility is that $\mathrm{S} 2$ may be able to perform a larger number of cognitive tasks regarding R than S1. Again, S1 needs to be able to perform a sufficient number of characteristic cognitive tasks as well, otherwise we could not attribute any understanding ${ }_{\mathrm{NT}}$ to $\mathrm{S} 1$ at all. Nevertheless, S1 and S2 may differ with regard to how well they are able to perform the cognitive tasks.

Arguably, however, differences of this sort are not what speakers have in mind in typical situations where they attribute different, competing, or conflicting understandings $\mathrm{sT}_{\mathrm{NT}}$ to two subjects. For example, suppose that Plato and one of his pupils both have suitable epistemic pro-attitudes towards Plato's theory of the transmigration of souls, and are able to fulfill a characteristic set of cognitive tasks with regards to it, but that Plato has a stronger

Footnote 12 (continued)

not (3), requires R to be correct; similarly, (2), but not (4), requires the subject's representation of $R$ to be correct. At this point an important difference between de Regt's notion of intelligibility and the notion of understanding $\mathrm{NT}_{\mathrm{NT}}$ also becomes apparent. While the former is a property of theories or representations more generally, the latter is directed at the phenomena themselves. For example, phlogiston theory may be intelligible to phlogiston theorists, while they have an understanding $\mathrm{NT}_{\mathrm{N}}$ of combustion. 
pro-attitude towards his pro-attitude, a better justification for it, or is better able to fulfill the cognitive tasks than the pupil. Would we, in this case, say that Plato and the pupil have different (or even competing or conflicting) understandings ${ }_{\mathrm{NT}}$ of the transmigration of souls? Probably not, I suppose. It seems that, at least typically, talk of different, competing, or conflicting understandings $\mathrm{NT}_{\mathrm{N}}$ implies the presence of different, competing, or conflicting representations. ${ }^{13}$

Let us now turn to the fact that, obviously, it makes a difference whether the representations are said to be 'conflicting', 'competing', or merely 'different'. Accordingly, it makes a difference whether S1's and S2's understandings ${ }_{\mathrm{NT}}$ are said to be 'conflicting', 'competing', or 'different'. Speakers can articulate slight nuances by describing the relationship between two subjects' understandings ${ }_{\mathrm{NT}}$ with either of these adjectives. ${ }^{14}$ If two representations are merely different, they need not necessarily be in tension. Both can be correct and equally adequate representations of P. For example, R1 and R2 could focus on different aspects of $\mathrm{P}$ in the following way: $\mathrm{R} 1$ makes some assumptions about certain aspects of $\mathrm{P}$ and remains silent about those aspects about which $\mathrm{R} 2$ makes some assumptions; and R2, conversely, remains silent about those aspects about which R1 makes some assumptions. ${ }^{15}$

In other cases, however, there is a tension between two understandings $\mathrm{NT}_{\mathrm{T}} /$ representations. We could call the strongest form of such tension 'conflict'. If R1 and R2 are said to be 'conflicting', then the correctness of one representation excludes the correctness of the other. In other words, if R1 is correct, R2 is incorrect, and vice versa-they cannot both be correct at the same time, although they can be incorrect at the same time. As a consequence, it is not possible for both $\mathrm{S} 1$ and $\mathrm{S} 2$ to understand $\mathrm{T}_{\mathrm{T}} \mathrm{P}$ if they have conflicting understanding $\mathrm{S}_{\mathrm{NT}}$ of $\mathrm{P}$. Note that the question of whether two representations are conflicting in this sense partially depends on what it means for a representation to be

\footnotetext{
13 However, could the differences between Plato and the pupil's ability to perform the necessary cognitive tasks not be more profound? Instead of being mere quantitative nuances (i.e., differences in how well the subjects perform the cognitive tasks), could they not be be the source of more substantial differences or tensions? I am inclined to think not; unless there are differences between their representations, there are no substantial differences or tensions between the subjects. For suppose that the different performance of the cognitive tasks would result in S1 believing (or accepting) a proposition p about the phenomenon that S2 does not believe (or accept). Then that belief (acceptance) would be a part of S1's representation of the phenomenon, but not a part of S2's. On the other hand, suppose that their different performances of the cognitive tasks do not result in the subjects having different beliefs (acceptances) about the phenomenon. In this case, it seems to me, there is no substantial difference or cognitive tension between them. So, either the subjects believe (accept) the same things about the phenomenon, in which case there is no substantial difference or tension, or they believe different propositions about it, in which case there may be a substantial difference or tension, but it is due to their having different representations.

14 There are further adjectives that can be used to describe the relationship between two peoples' understandings $\mathrm{s}_{\mathrm{NT}}$ or representations that seem to be more or less equivalent to the three that are mentioned in DIFF. For example, the phrase 'alternative understandings $\mathrm{ST}_{\mathrm{NT}} /$ representations', arguably, is more or less equivalent to 'different understandings $\mathrm{NT}_{\mathrm{NT}} /$ representations'; 'contesting understandings $_{\mathrm{NT}} /$ representations' is more or less equivalent to 'competing understanding $\mathrm{S}_{\mathrm{NT}} /$ representations'; and 'incompatible understandings $\mathrm{ST}_{\mathrm{NT}} /$ representations' is more or less equivalent to 'conflicting understandings $\mathrm{NT}_{\mathrm{NT}} /$ representations'.

15 For example, think of two theories of a phenomenon, one of which focuses on its causes, while the other focuses on its effects. Or think of theories that give different (but mutually compatible) accounts of some type of human behavior, either in social, or psychological, or neurological terms, respectively. It might be worth noting that similar things apply to explanatory understanding ${ }_{\mathrm{NT}}$ as well. One can have different but compatible explanatory understandings ${ }_{\mathrm{NT}}$ of why a person behaved the way she did (such as neurophysiological, psychological, or sociological understandings $\mathrm{S}_{\mathrm{NT}}$ ), or different but compatible explanatory understandings $\mathrm{S}_{\mathrm{NT}}$ of why a house burned down (such as an understanding $\mathrm{NT}_{\mathrm{N}}$ in terms of the physical/technical details or an understanding $\mathrm{NT}_{\mathrm{T}}$ in terms of an arsonist's motivation).
} 
correct (recall that I use the phrase 'correct representation' in the sense of 'representation that affords tethered understanding'). For suppose that a representation's correctness implies that it is completely true. In this case, R1 and R2 cannot be correct at the same time if there is a single contradiction between them (i.e., a proposition such that R1 assumes its truth while R2 assumes its falsity). On the other hand, if it should be the case that a representation can be correct without being completely true, single contradictions between R1 and R2 do not exclude the possibility that they are both correct (for example, R1 and R2 could be consistent with respect to their essential assumptions, but inconsistent with respect to some of their peripheral assumptions). Thus, although $\mathrm{UND}_{\mathrm{NT}}$ does not have a tether component, the way the tether component is specified in $\mathrm{UND}_{\mathrm{T}}$ has an indirect influence on what it means for two understandings $\mathrm{sT}_{\mathrm{NT}}$ to be conflicting.

While a conflict between two representations is the strongest form of tension between them, there can be tensions that do not require conflict. I suggest that two representations are 'competing' when there is tension between them, which leaves it open whether they are conflicting or not. If R1 and R 2 are competing but non-conflicting, then there is tension between them, but it is possible for them to be both correct at the same time. Accordingly, it is possible for both $\mathrm{S} 1$ and $\mathrm{S} 2$ to have some understanding $\mathrm{T}_{\mathrm{T}}$ of $\mathrm{P}$ if they have competing understandings $\mathrm{NT}_{\mathrm{N}}$ of it. How such non-conflicting tensions can be explained again depends on what it means for a representation to be correct. If a representation's correctness does not require the truth of its peripheral assumptions, then both R1 and R2 can be correct, despite possible inconsistencies between their peripheral assumptions. Even if a representation's correctness does require its complete truth, I think it is possible that R1 and R2 can be competing but non-conflicting. In general, two representations of $\mathrm{P}$ may be said to be competing if each claims to provide a better, more adequate, account of $\mathrm{P}$. Thus, for example, a representation may claim to be better than another, empirically equivalent representation on the grounds that it is simpler, more elegant, more fruitful, or broader in scope (that is, if it scores better with respect to some epistemic value(s) in Kuhn's (1977) sense).

A conflict between two representations is the strongest form of discrepancy between them. Conflicting representations are always competing representations (but not vice versa), and competing representations are always different representations (but not vice versa). The same logical ordering results in different, competing, and conflicting understandings $\mathrm{NT}_{\mathrm{NT}}$.

Some but not all cases of different understandings ${ }_{\mathrm{NT}}$ should be described as being 'disagreement-like'. As I said, there are cases in which there is no tension between different understandings $\mathrm{NT}_{\mathrm{NT}}$. If we take disagreement-likeness to necessarily involve some sort of tension, it follows that these situations are not disagreement-like. However, if two understandings $\mathrm{s}_{\mathrm{NT}}$ are competing or conflicting, there is a tension between them, so it seems natural to describe them as disagreement-like.

In my view, DIFF captures what is typically meant when one says that two people "have different, competing, or conflicting understandings" of a phenomenon or subject matter. Similarly, we can make sense of what we typically mean when we say that S1 and S2 "share the same understandings" of a phenomenon P. In this case, S1 and S2 have suitable epistemic pro-attitudes towards an identical representation $\mathrm{R}$ of $\mathrm{P}$ and are able to perform the characteristic cognitive tasks with regard to it. However, as already indicated, this does not imply that there are no discrepancies whatsoever between S1 and S2's understandings ${ }_{\mathrm{NT}}$. If two people share the same understandings $\mathrm{NT}_{\mathrm{NT}}$ of $\mathrm{P}$, one of the subjects could have a stronger-than-necessary epistemic pro-attitude towards the 
representation or be able to perform more-than-necessary cognitive tasks than the other subject.

\section{Different, Competing, and Conflicting Understandings $s_{\mathrm{NT}}$ and Scientific Pluralism}

The achievement of understanding ${ }_{\mathrm{T}}$ is a fundamental intrinsic epistemic goal in scienceperhaps even its most important goal (see, for example, Salmon 1998; Kvanvig 2003; Dellsén 2016b; Elgin 2017). Arguably, developing understandings ${ }_{\mathrm{NT}}$ is a less important intrinsic scientific goal, if it is an intrinsic goal at all. Typically, scientists do not develop understandings $_{\mathrm{NT}}$ of some phenomenon for their own sake, but because they want to understand $_{\mathrm{T}}$ that phenomenon. As a result, they favor those understanding $\mathrm{s}_{\mathrm{NT}}$ that they assume involve correct representations (much like they favor those beliefs that they take to be true). If understanding $\mathrm{NT}_{\mathrm{NT}}$ is an ingredient of understanding $\mathrm{T}_{\mathrm{T}}$ in a similar way that belief is an ingredient of knowledge-, we may say that developing understandings ${ }_{\mathrm{NT}}$ first and foremost is a precondition or requirement for achieving understanding $\mathrm{T}_{\mathrm{T}}$. In a similar way in which scientists need to form beliefs if they aim to acquire knowledge, they need to develop understandings $\mathrm{NT}_{\mathrm{NT}}$ if they aim to achieve understanding $\mathrm{T}_{\mathrm{T}}$.

The analogy between the understanding $\mathrm{NT}_{\mathrm{T}}$-understanding $\mathrm{T}_{\mathrm{T}}$ relationship and the beliefknowledge relationship goes even further. From a socio-epistemological point of view, there are good reasons to suppose that doxastic disagreement is valuable for science because it helps scientific communities acquire knowledge about the world (see, for example, De Cruz and De Smedt 2013). Similarly, as I shall argue in this section, a diversity of different, competing, and conflicting understandings $\mathrm{ST}_{\mathrm{NT}}$ within scientific communities is valuable because it helps them achieve their goal of understanding ${ }_{\mathrm{T}}$ the phenomena within their fields of research. Indeed, I think that some of the reasons supporting this claim are familiar from the debate about scientific pluralism. In his discussion about why epistemic diversity is good for science, Chang (2012) distinguishes between 'benefits of toleration' and 'benefits of interaction'. This distinction can be applied rather straightforwardly to understanding $\mathrm{NT}_{\mathrm{NT}}$ and its relationship to understanding $\mathrm{T}_{\mathrm{T}}$. The idea behind benefits of toleration is that we should welcome epistemic diversity even in the absence of interactions between scientists from opposing camps. When applied to belief, one of the main arguments is that, typically, it is uncertain whether a scientific belief shared by a number of scientists is true. Even beliefs that seem to be well justified at a certain time can later turn out to be false. Something similar can be put forward for understanding ${ }_{\mathrm{T}}$. Phenomena that appeared to be well understood $\mathrm{T}_{\mathrm{T}}$ can turn out to be poorly understood $\mathrm{T}_{\mathrm{T}}$. In response, scientific pluralists will recommend that scientists should hedge their bets. Applied to understanding $_{\mathrm{T}}$, scientists (or more appropriately, scientific communities) should aim at a diversity of understandings $\mathrm{NT}_{\mathrm{NT}}$ in order to be better prepared for situations in which an understanding $_{\mathrm{NT}}$ that seemed to be best suited for making sense of a certain phenomenon turns out to be misguided. If there are alternative understandings ${ }_{\mathrm{NT}}$ of the same phenomenon on the market, scientists can draw on them and explore their respective prospects of providing better accounts.

If there are interactions between proponents of different understandings $\mathrm{sT}_{\mathrm{NT}}$, additional benefits-benefits of interaction-are possible. In particular, proponents of different understandings $\mathrm{S}_{\mathrm{NT}}$ can subject other understandings $\mathrm{s}_{\mathrm{NT}}$ of the same phenomenon to 
critical scrutiny and identify their weaknesses. As a consequence, proponents of these other understanding $\mathrm{s}_{\mathrm{NT}}$ can learn from this criticism and improve their own understanding $\mathrm{s}_{\mathrm{NT}}$.

One can ask which of the definitional components of understanding $\mathrm{NT}_{\mathrm{T}}$ are involved in producing the epistemic benefits (be they benefits of toleration or of interaction). According to $\mathrm{UND}_{\mathrm{NT}}$, understanding $\mathrm{NT}_{\mathrm{NT}}$ has an epistemic-pro-attitude component and a cognitive component. This implies that, if there is a diversity of understandings $\mathrm{NT}_{\mathrm{NT}}$ of a phenomenon $\mathrm{P}$, there are different scientists who, first, have epistemic pro-attitudes towards different representations $\mathrm{R} 1, \mathrm{R} 2, \ldots$ or $\mathrm{Rn}$ of $\mathrm{P}$, and second, are able to perform the characteristic cognitive tasks with regard to either R1, R2, .. or Rn of P. So which of these aspects is relevant for producing the epistemic benefits? I submit that the answer is that both can be relevant. The first aspect is relevant, for example, because if different scientists have epistemic pro-attitudes towards different representations, they are motivated to pursue their own favored understanding $_{\mathrm{NT}}$ and to criticize their rivals' understandings $\mathrm{NT}_{\mathrm{NT}}$. The second aspect is relevant because one understanding $\mathrm{NT}_{\mathrm{NT}}$ may require performing different cognitive tasks than another understanding $\mathrm{NT}_{\mathrm{NT}}$. Even if one does not take a theory to be an adequate representation of a phenomenon, dealing with that theory or learning how it works can enhance one's cognitive capacities. And an enhancement of one's capacities may further improve one's understanding $_{\mathrm{T}}$. It may well be that a healthy scientific discourse requires not only a sufficiently large set of diverging beliefs and ideas, but also a sufficiently large set of cognitive skills that the scientists are able to perform. A diversity of understandings $\mathrm{NT}_{\mathrm{NT}}$ has the potential to enlarge this set and thus has significant value for that discourse. In sum, a diversity of understandings $\mathrm{N}_{\mathrm{NT}}$ promotes the achievement of understanding $\mathrm{T}_{\mathrm{T}}$ both because it helps scientists to improve their representations and because it helps them to increase the set of cognitive tasks they can perform.

A further relevant question is the following: given a certain phenomenon $\mathrm{P}$, should scientific communities aim at incorporating a diversity of understanding $\mathrm{s}_{\mathrm{NT}}$ of $\mathrm{P}$ that are conflicting, or a diversity of understanding $\mathrm{s}_{\mathrm{NT}}$ of $\mathrm{P}$ that are competing without being conflicting, or a diversity of understandings $\mathrm{s}_{\mathrm{NT}}$ of $\mathrm{P}$ that are merely different without being competing? I think the answer is that scientific communities can benefit from a diversity of different, non-competing understanding $\mathrm{s}_{\mathrm{NT}}$, they can benefit in further ways from the presence of competing, non-conflicting understandings $\mathrm{NT}_{\mathrm{NT}}$, and there are additional benefits that can accrue from the presence of conflicting understandings $\mathrm{NT}_{\mathrm{NT}}$. For example, if two understandings $\mathrm{s}_{\mathrm{NT}}$ are compatible because, say, they focus on different aspects of a phenomenon, proponents of the understandings $\mathrm{N}_{\mathrm{NT}}$ can learn from each other that none provides a full account of the phenomenon. And if two understandings ${ }_{\mathrm{NT}}$ are competing or conflicting, studying the other understanding ${ }_{\mathrm{NT}}$ gives their proponents the opportunity to identify potential weaknesses in their own accounts.

Allow me finally some brief remarks on a question that has preoccupied many epistemologists in recent years. The central question in the debate on peer disagreement is this: if two epistemic peers learn from each other that they hold contradictory beliefs about a certain proposition $\mathrm{p}$, how should they rationally react? It seems obvious that we can ask a similar question with regard to different understandings $\mathrm{NT}_{\mathrm{NT}}$. If two scientific peers learn that they advocate different understandings $\mathrm{N}_{\mathrm{NT}}$ of $\mathrm{P}$, how should they reasonably react? I shall not here attempt to provide a comprehensive answer to this question. I shall, however, briefly explore some of the challenges facing any attempt to provide a comprehensive answer. Note, first, that in paradigmatic cases of doxastic peer disagreements there are arguably three possible reactions for someone who learns that there is an epistemic peer who disagrees about p: remaining steadfast, i.e. maintaining one's doxastic stance towards 
p; adopting a neutral or agnostic stance; or adopting the other peer's doxastic stance. ${ }^{16}$ In cases in which S1 learns that an epistemic peer S2 has a different understanding $\mathrm{NT}_{\mathrm{NT}}$ of a phenomenon, the situation is more complex. For one, which reaction is rational depends on whether S1 and S2's understandings $\mathrm{NT}_{\mathrm{T}}$ are (i) merely different without being competing, (ii) competing without being conflicting, or (iii) conflicting. S1 and S2's understandings ${ }_{\mathrm{NT}}$ could be different without being competing because the representations underlying their understanding $\mathrm{s}_{\mathrm{NT}}$ concern different aspects of the phenomenon in question. One possible reason why S1 and S2 prefer their representations is because their epistemic interests differ. S1 might be interested in certain aspects of P, while S2 is interested in other aspects. So, given their interests, it might well be reasonable for the subjects to 'remain steadfast' (if we want to apply this terminology here). If the understandings $\mathrm{NT}_{\mathrm{NT}}$ are competing without being conflicting, there seem to be situations in which it is also reasonable for the subjects to remain steadfast, as well as other situations in which it might be reasonable for them to reach some conciliation. As I argued in Sect. 4, understandings ${ }_{\mathrm{NT}}$ can be competing because they account for different epistemic or non-epistemic values. Given that different subjects may have divergent preferences for these values, and given that any particular weighting of them is not (or need not necessarily be) more or less rational than any other one, it may well be rational for the subjects to keep to their understanding $\mathrm{s}_{\mathrm{NT}}$. However, it is also possible that the subjects share the same pattern of preferences for the relevant values. In this case, some conciliation may be called for because one of the understandings $\mathrm{NT}_{\mathrm{NT}}$ may objectively be better suited than the other to account for the pattern of preferences that both subjects share. Finally, if the understandings ${ }_{\mathrm{NT}}$ are conflicting, the situation arguably is similar to cases of doxastic disagreement. So whatever reasons one might have in favor of either steadfast or conciliatory views about doxastic disagreements will be applicable in this type of situation.

Another reason why analyzing cases of differing understandings ${ }_{\mathrm{NT}}$ may be more complex than analyzing doxastic disagreements is that the notion I tried to capture in DIFF is more complex than the notion of a doxastic disagreement. Doxastic disagreements involve just one proposition on which the subjects adopt different doxastic stances. By contrast, cases of differing understandings $\mathrm{N}_{\mathrm{NT}}$ involve two different representations towards which the subjects may have a variety of epistemic stances. For example, if belief or acceptance is the epistemic pro-attitude required for understanding $\mathrm{NT}_{\mathrm{NT}}, \mathrm{S} 1$ might believe/accept that R1 is correct, and S1 might believe, accept, or merely have a positive degree of belief that R2 is incorrect; and so on for S2 and her stances towards R1 and R2. And the situation's complexity increases if we consider the various ways that subjects might change their epistemic stance on the representations (from belief to agnosticism, from belief to acceptance, and so on). Furthermore, possible reactions might also include the cognitive component. S1 might take R2 not to be a correct representation, while still benefiting from dealing with S2's understanding ${ }_{\mathrm{NT}}$. The reason is that, as argued above, one's cognitive capacities can be enhanced even by dealing with an incorrect theory or learning how an incorrect theory is supposed to work.

Finally, let me point to yet another difficulty. When we ask which reaction is rational in the face of a peer's different understanding $\mathrm{NT}_{\mathrm{T}}$ of a phenomenon $\mathrm{P}$, we should take into account the possibility of a discrepancy between individual and social rationality. Individually, a certain reaction may be rational for the subject in the sense that the reaction

\footnotetext{
${ }^{16}$ In terms of degrees of belief, the options are maintaining one's degree of belief, adopting the other peer's degree of belief, or switching to another degree between the previous one and that of the peer.
} 
increases the chances of her achieving her individual epistemic goal of understanding ${ }_{T} P$. For example, suppose that the peer's understanding ${ }_{N T}$ is better suited for understanding ${ }_{T} P$ than the understanding $\mathrm{NT}_{\mathrm{N}}$ she previously favored. In this light, it seems to be rational for her to adopt the peer's understanding ${ }_{\mathrm{NT}}$. On the other hand, I have argued in this section that a diversity of understanding $\mathrm{s}_{\mathrm{NT}}$ within a scientific community is epistemically beneficial because it may increase the probability that the community as a whole achieves its epistemic goals. From the perspective of this social rationality, it may be good if she is steadfast and sticks to her previous understanding $\mathrm{NT}_{\mathrm{NT}}$. This may seem to be the rational behavior in a more social sense of the word, that is, in the sense that it helps the community achieve its epistemic goals.

\section{Conclusion}

I have argued that, typically, sentences of the form "S1 and S2 have different/competing/ conflicting understandings of P" can be uttered with no commitment to whether any of the two subjects understand the phenomenon in the sense of 'understanding' that philosophers usually have in mind. This observation can be explained by distinguishing a tethered notion of understanding, understanding $\mathrm{T}_{\mathrm{T}}$, from a non-tethered notion, understanding $\mathrm{NT}_{\mathrm{NT}}$. If someone has an understanding $\mathrm{NT}_{\mathrm{NT}}$ of some phenomenon $\mathrm{P}$, she has a suitable epistemic proattitude towards a representation $\mathrm{R}$ of $\mathrm{P}$ and is able to perform a characteristic set of cognitive tasks with respect to R. But unlike understanding ${ }_{\mathrm{T}}$, $\mathrm{R}$ need not be correct. A situation in which two subjects are said to have different, competing, or conflicting understandings $\mathrm{N}_{\mathrm{NT}}$ of $\mathrm{P}$ is a situation in which one subject has a certain understanding $\mathrm{NT}_{\mathrm{T}}$ of $\mathrm{P}$ and the other subject has another understanding $\mathrm{NT}_{\mathrm{T}}$ of $\mathrm{P}$ based on a different, competing, or conflicting representation. I have argued that in scientific practice the relevance of a diversity of different, competing, or conflicting understanding $\mathrm{s}_{\mathrm{NT}}$ derives from the fact that understanding $\mathrm{T}_{\mathrm{T}}$ is an important (or maybe the most important) goal in science and that a diversity of different, competing, or conflicting understanding $\mathrm{s}_{\mathrm{NT}}$ can help scientific communities achieve this goal. Specifically, the benefits of such diversity can result (1) from there being different scientists who have epistemic pro-attitudes towards different, competing, or conflicting representations of a certain phenomenon $\mathrm{P}$, and (2) from there being different scientists who are able to perform the characteristic set of cognitive tasks with regard to different, competing, or conflicting representations of P. Moreover, the benefits can be benefits of toleration and of interaction.

Funding Open Access funding enabled and organized by Projekt DEAL.

Open Access This article is licensed under a Creative Commons Attribution 4.0 International License, which permits use, sharing, adaptation, distribution and reproduction in any medium or format, as long as you give appropriate credit to the original author(s) and the source, provide a link to the Creative Commons licence, and indicate if changes were made. The images or other third party material in this article are included in the article's Creative Commons licence, unless indicated otherwise in a credit line to the material. If material is not included in the article's Creative Commons licence and your intended use is not permitted by statutory regulation or exceeds the permitted use, you will need to obtain permission directly from the copyright holder. To view a copy of this licence, visit http://creativecommons.org/licenses/by/4.0/. 


\section{References}

Audi, R. (2013). Cognitive Disparities: Dimensions of Intellectual Diversity and the Resolutions of Disagreement. In: D. Christensen, \& J. Lackey (Eds.), The Epistemology of Disagreement: New Essays (pp. 205-222). New York: Oxford University Press.

Baumberger, C., Beisbart, C., \& Brun, G. (2017). What is understanding? An overview of recent debates in epistemology and philosophy of science. In: S. Grimm, C. Baumberger, \& S. Ammon (Eds.), Explaining Understanding (pp. 1-34). London: Routledge.

Baumberger, C., \& Brun, G. (2017). Dimensions of objectual understanding. In: S. Grimm, C. Baumberger, \& S. Ammon (Eds.), Explaining understanding (pp. 165-189). London: Routledge.

Chang, H. (2012). Is Water H2O? Evidence, Realism and Pluralism. Dordrecht: Springer.

De Cruz, H., \& De Smedt, J. (2013). The value of epistemic disagreement in scientific practice. The case of Homo floresiensis. Studies in History and Philosophy of Science, 44, 169-177.

Dellsén, F. (2016a). Understanding without justification or belief. Ratio, 30, 239-254.

Dellsén, F. (2016b). Scientific progress: knowledge versus understanding. Studies in History and Philosophy of Science, 56, 72-83.

De Regt, H. (2017). Understanding Scientific Understanding. Oxford: Oxford University Press.

De Regt, H., Leonelli, S., \& Eigner, K. (Eds.) (2009). Scientific Understanding. Pittsburgh: University of Pittsburgh Press.

Elgin, C. (2007). Understanding and the facts. Philosophical Studies, 132, 33-42.

Elgin, C. (2012). Understanding's Tethers. In: C. Jäger, \& W. Löffler (Eds.), Epistemology: Contexts, Values, Disagreement (pp. 131-146). Frankfurt: Ontos.

Elgin, C. (2017). True Enough. Oxford: Oxford University Press.

Gijsbers, V. (2013). Understanding, explanation, and unification. Studies in History and Philosophy of Science, 44, 516-522.

Gordon, E. (2017). Social Epistemology and the Acquisition of Understanding. In: S. Grimm, C. Baumberger, S. Ammon (Eds.), Explaining Understanding (pp. 293-317). London: Routledge.

Gordon, E. (2020). Understanding in Epistemology. In: The Internet Encyclopedia of Philosophy, www.iep. utm.edu/understa, 4.12.20.

Greco, J. (2014). Episteme: Knowledge and Understanding. In: K. Timpe, \& C. Boyd (Eds.), Virtues and their vices (pp. 285-301). Oxford: Oxford University Press.

Grimm, S. (2006). Is understanding a species of knowledge? British Journal of Philosophy of Science, 57, $515-535$.

Grimm, S. (2010). The goal of understanding. Studies in History and Philosophy of Science, 41, 337-344.

Grimm, S. (2011). Understanding. In: S. Bernecker, \& D. Pritchard (Eds.), The Routledge Companion to Epistemology (pp. 84-94). London, New York: Routledge.

Grimm, S. (Ed.) (2018). Making Sense of the World. Oxford: Oxford University Press.

Grimm, S., Baumberger, C., Ammon, S. (Eds.) (2017). Explaining Understanding. London.

Hazlett, A. (2018). Understanding and structure. In: S. Grimm (Ed.), Making Sense of the World (pp. 135158). Oxford: Oxford University Press.

Hills, A. (2009). Moral testimony and moral epistemology. Ethics, 120, 94-127.

Huvenes, T. T. (2013). Disagreement without error. Erkenntnis, 79, 143-154.

Huvenes, T. T. (2017). On disagreement. In: J. Ichikawa (Ed.), The Routledge Handbook of Epistemic Contextualism (pp. 272-281). New York: Routledge.

Kelp, C. (2017). Towards a Knowledge-Based Account of Understanding. In: S. Grimm, C. Baumberger, \& S. Ammon (Eds.), Explaining Understanding (pp. 251-271). London: Routledge.

Khalifa, K., \& Gadomski, M. (2013). Understanding as explanatory knowledge: The case of Bjorken scaling. Studies in the History and Philosophy of Science, 44, 384-392.

Kuhn, T. (1977). Objectivity, Value Judgment, and Theory Choice. In: The Essential Tension. Selected Studies in Scientific Tradition and Change (pp. 320-339). Chicago: University of Chicago Press.

Kvanvig, J. (2003). The Value of Knowledge and the Pursuit of Understanding. New York: Cambridge University Press.

Lawler, I. (2019). Scientific understanding and felicitous legitimate falsehoods. Synthese. https://doi.org/10. 1007/s11229-019-02495-0.

Mizrahi, M. (2012). Idealizations and scientific understanding. Philosophical Studies, 160, $237-252$.

Newman, M. (2012). An inferential model of scientific understanding. International Studies in the Philosophy of Science, 26, 1-26.

Pritchard, D. (2009). Knowledge, understanding, and epistemic value. Royal Institute of Philosophy Supplement, 64, 19-43.

Rice, C. (2019). Understanding realism. Synthese. https://doi.org/10.1007/s11229-019-02331-5. 
Rosenberg, J. F. (1981). On Understanding the Difficulty in Understanding Understanding. In: H. Parrett, \& J. Bouveresse (Eds.), Meaning and Understanding (pp. 29-43). Berlin/New York: De Gruyter.

Salmon, W. (1998). The Importance of Scientific Understanding. Causality and Explanation (pp. 79-91). New York: Oxford University Press.

Strevens, M. (2013). No understanding without explanation. Studies in History and Philosophy of Science, $44,510-515$.

Wilkenfeld, D. (2013). Understanding as representation manipulability. Synthese, 190, 997-1016.

Wilkenfeld, D. (2017). Understanding without believing. In: S. Grimm, C. Baumberger, \& S. Ammon (Eds.), Explaining understanding (pp. 318-333). London: Routledge.

Publisher's Note Springer Nature remains neutral with regard to jurisdictional claims in published maps and institutional affiliations. 